University of Nebraska - Lincoln

DigitalCommons@University of Nebraska - Lincoln

Biological Systems Engineering: Papers and

Publications

Biological Systems Engineering

2011

Flow and transport experiments for a streambank seep originating from a preferential flow pathway

\author{
Garey A. Fox \\ Oklahoma State University - Main Campus, gafox2@ncsu.edu \\ Derek M. Heeren \\ University of Nebraska-Lincoln, derek.heeren@unl.edu \\ Ronald B. Miller \\ Oklahoma State University, ron.miller@okstate.edu \\ Aaron R. Mittelstet \\ Oklahoma State University, Stillwater, amittelstet2@unl.edu \\ Daniel E. Storm \\ Oklahoma State University - Main Campus, dan.storm@okstate.edu
}

Follow this and additional works at: https://digitalcommons.unl.edu/biosysengfacpub

Part of the Biological Engineering Commons

Fox, Garey A.; Heeren, Derek M.; Miller, Ronald B.; Mittelstet, Aaron R.; and Storm, Daniel E., "Flow and transport experiments for a streambank seep originating from a preferential flow pathway" (2011). Biological Systems Engineering: Papers and Publications. 224.

https://digitalcommons.unl.edu/biosysengfacpub/224

This Article is brought to you for free and open access by the Biological Systems Engineering at DigitalCommons@University of Nebraska - Lincoln. It has been accepted for inclusion in Biological Systems Engineering: Papers and Publications by an authorized administrator of DigitalCommons@University of Nebraska Lincoln. 


\title{
Flow and transport experiments for a streambank seep originating from a preferential flow pathway
}

\author{
G. A. Fox, D. M. Heeren, R. B. Miller, A. R. Mittelstet, and D. E. Storm \\ Department of Biosystems and Agricultural Engineering, Oklahoma State University, \\ 120 Agricultural Hall, Stillwater, OK 74078-6016, United States \\ Corresponding author - G. A. Fox, garey.fox@okstate.edu \\ Emails - D. M. Heeren, derek.heeren@unl.edu ; R. B. Miller, ron.miller@okstate.edu ; \\ A. R. Mittelstet, aaron.mittelstet10@okstate.edu ; D. E. Storm, $\underline{\text { dan.storm@okstate.edu }}$
}

\begin{abstract}
Streambank seeps commonly originate from localized heterogeneity or preferential flow pathways (PFPs) in riparian floodplains. However, limited field data have been reported on ground water seep flows and solute transport to seeps from PFPs. The objective of this research was to build upon previous floodplain-scale investigations of PFPs by analyzing seep discharge and transport characteristics through a single PFP. An important research question was whether this PFP could be conceptualized as a homogeneous, one-dimensional flow path. Streambank seep discharge measurements were obtained by inducing a hydraulic head in a trench injection system. Also, co-injection of Rhodamine WT (RhWT) and a potassium chloride $(\mathrm{KCl})$ tracer over a 60-min period was used to investigate transport dynamics. Seep discharge and breakthrough curves for electrical conductivity (EC) and RhWT were measured at the streambank using a lateral flow collection device. The breakthrough curves were fit to one-dimensional convectivedispersion equations (CDEs) to inversely estimate solute transport parameters. The PFP from which the seep originated was clean, coarse gravel $(6 \%$ by mass less than $2.0 \mathrm{~mm}$ ) surrounded by gravel with finer particles ( $20 \%$ by mass less than $2.0 \mathrm{~mm})$. Located approximately $2 \mathrm{~m}$ from the trench, the seep $(50 \mathrm{~cm}$ by $10 \mathrm{~cm}$ area) required at least $40 \mathrm{~cm}$ of hydraulic head for flow to emerge at the streambank. At a higher hydraulic head of $125 \mathrm{~cm}$, seep discharge peaked at $3.5 \mathrm{~L} / \mathrm{min}$. This research verified that localized PFPs can result in the rapid transport of water (hydraulic conductivity on the order of $400 \mathrm{~m} / \mathrm{d}$ ) and solutes once reaching a sufficient near-bank hydraulic head. A one-dimensional equilibrium CDE was capable of simulating the $\mathrm{EC}\left(R^{2}=0.94\right)$ and $R h W T\left(R^{2}=0.91\right)$ breakthrough curves with minimal RhWT sorption (distribution coefficient, $K_{d}$, equal to $0.1 \mathrm{~cm}^{3} / \mathrm{g}$ ). Therefore, the PFP could be conceptualized as a one-dimensional, homogenous flow and transport pathway. These results are consistent with previous research observing larger-scale phosphorus transport.
\end{abstract}

Keywords: Contaminant transport, Preferential flow, Rhodamine WT, Riparian floodplain, Seepage

\section{Introduction}

Most studies of riparian zone hydrology and contaminant fate and transport have focused on the more easily observed and understood Hortonian flow mechanism. Historically, limited research has been reported on ground water seepage and solute transport by the preferential flow pathways (PFPs) from which ground water seeps commonly originate. The reason for limited research has been the inherent difficulty in identifying such points of heterogeneity in the near-bank ground water zone (Fox and Wilson, 2010). As pointed out by Wagenet and Chen (1998), rapid pulses of contaminants may occur from a small fraction of fast flow pathways.
Large-scale heterogeneity in riparian floodplains has been frequently recognized even within coarse gravel deposits (Naiman et al., 2005; Fuchs et al., 2009; Heeren et al., 2010; Miller et al., 2010). Paleochannels, or linear deposits of coarsegrained sediments, exist across floodplains and link modern channel flows to distal floodplain areas (Poole et al., 1997; Naiman et al., 2005). Stanford and Ward (1992) and Amoros and Bornette (2002) pointed out that surface water/ground water exchanges link stream channels to the entire floodplain. Modica et al. (1998) documented the influence of heterogeneity in riparian areas next to streams and their effect on source area locations for ground water seepage and the distributions of ground water residence times. 
More recent research has further documented that nearbank ground water discharges to streams at focused as opposed to diffuse points. This focused seepage can influence flow and sediment, nutrient, and contaminant loads entering streams (Duval and Hill, 2007; Fox et al., 2007; Wilson et al., 2007; LaSage et al., 2008; Fuchs et al., 2009; O'Driscoll and DeWalle, 2010). The Committee on Hydrologic Sciences of the National Research Council (NRC, 2004) identified several research needs in regard to ground water fluxes across interfaces and prioritized the need to determine the relative importance of diffuse versus focused recharge/discharge in specific hydrogeologic settings (LaSage et al., 2008).

One mechanism for the occurrence of focused discharge points is due to PFPs in the alluvial subsurface (Duval and Hill, 2006, 2007; Fox et al., 2007; Wilson et al., 2007; LaSage et al., 2008; Chu-Agor et al., 2008, 2009; Heeren et al., 2010). Duval and Hill $(2006,2007)$ used bromide and nitrate injection into a streambank to document streambank seepage in poorly sorted gravel PFPs in two riparian floodplains. Their primary conclusion was that sustained seepage during low flow conditions may impact riparian zone nitrogen cycling. Fox et al. (2007) and Wilson et al. (2007) studied ground water seepage in the Mississippi Embayment leading to streambank failures and demonstrated that focused discharge can significantly impact lateral channel migration. Similar conclusions regarding seepage impacts on bank stability were made by LaSage et al. (2008) for a Coastal Plain stream in western Kentucky and by Lindow et al. (2009) for a stream in North Carolina.

Furthermore, consider that the primary mechanism by which phosphorus is transported from uplands to streams is usually considered to be surface runoff, with subsurface transport assumed negligible. Fuchs et al. (2009) investigated subsurface movement of phosphorus in riparian floodplains in eastern Oklahoma with alluvial, gravel subsoils. Phosphorus has been a primary water quality concern in this watershed (Andrews et al., 2009). Their work included a trench injection and monitoring system approximately 15-20 m from the Barren Fork Creek with observation wells installed within a 7-8 m radius of the trench. The dimensions of the trench were approximately $0.5 \mathrm{~m}$ wide by $2.5 \mathrm{~m}$ long by $1.2 \mathrm{~m}$ deep. The bottom of the trench was located approximately $25-50 \mathrm{~cm}$ below the interface between the topsoil and gravel layers. The bottom was left open to allow water to infiltrate directly into the gravel layer. They discovered that the movement of a Rhodamine WT (RhWT) and phosphorus co-injection occurred rapidly in PFPs. At the same riparian floodplain site, Heeren et al. (2010) investigated the floodplain-scale transport of RhWT along a PFP, infiltration of RhWT into the alluvial ground water system, and then transport in the alluvial system as influenced by the floodplain-scale stream/aquifer dynamics. They concluded that spatially variable PFPs, even in the coarse gravel subsoils, affected water level gradients and the distribution of dye into the shallow groundwater system.

The objective of this research was to build upon the previous floodplain-scale investigations of PFPs (Fuchs et al., 2009; Heeren et al., 2010) by analyzing seep discharge and transport characteristics through a single PFP. A trench injection system was used to artificially induce ground water heads on the alluvial system with: (1) simultaneous co-injection of potassium chloride $(\mathrm{KCl})$ tracer and RhWT, (2) measurement of the seep discharge, and (3) development of breakthrough curves for RhWT and electrical conductivity (EC) (see Supplemental video, Streambank Seep).

Unique to this research was the quantification of PFP hydraulic parameters, the determination of the required hydraulic head required to induce seepage flow through the PFP, and the investigation of flow and transport dynamics in this spe- cific PFP as opposed to the larger-scale studies previously mentioned (Fuchs et al., 2009; Heeren et al., 2010). The trench injection system allowed for a unique analysis of this identified PFP through inverse modeling with both equilibrium and nonequilibrium transport models. A significant research question was whether the gravel PFP could be conceptualized as a homogeneous, one-dimensional flow path, assessed based on the ability of such models to predict the observed concentration breakthrough for the tracer and RhWT. Finally, these inversely estimated parameters provided information on the potential transport of more reactive solutes (e.g., phosphorus) through PFPs.

\section{Materials and methods}

\subsection{Barren Fork Creek floodplain site}

The study site was located in a riparian floodplain in the Ozark region of northeastern Oklahoma adjacent to the Barren Fork Creek. The erosion of carbonate bedrock (primarily limestone) by slightly acidic water has left a large residuum of chert gravel in Ozark soils, with floodplains generally consisting of coarse chert gravel overlain by a mantle $(1-300 \mathrm{~cm})$ of gravelly loam or silt loam. The site (Figure 1, latitude: $35.90^{\circ}$, longitude: $-94.85^{\circ}$ ) was located immediately downstream of the Eldon Bridge US Geological Survey (USGS) gage station 07197000. With a watershed size of $845 \mathrm{~km}^{2}$, the Barren Fork Creek site has a median daily flow of $3.6 \mathrm{~m}^{3} / \mathrm{s}$.

Fuchs et al. (2009) and Heeren et al. (2010) demonstrated large-scale (i.e., greater than $10 \mathrm{~m}$ ) preferential movement of RhWT and potassium phosphate solution in the coarse gravel substrate at the site, hypothesized to be due to a number of subsurface PFPs. Heeren et al. (2010) also performed floodplain-scale electrical resistivity imaging which indicated the presence of a layer of clean, coarse gravel at the location of the PFP. Disturbed gravel samples were obtained from the streambank for the seep and soil material surrounding the seep. Percent of soil particles less than $2.0 \mathrm{~mm}$ in the PFP and in streambank samples surrounding the PFP were approximately $6 \%$ and $20 \%$ by mass, respectively (Heeren et al., 2010).

Significant streambank erosion since the original trench installation in 2007 had resulted in lateral movement of the creek towards the trench and exposed a single, identifiable PFP adjacent to the streambank (Figure 1). At the time of this experiment, the trench was approximately $2.0 \mathrm{~m}$ away from the streambank with many of the observation wells installed by Fuchs et al. (2009) and Heeren et al. (2010) removed by streambank migration. The exposure of this single PFP allowed a quantification of a single PFP's hydraulic parameters, the determination of the required hydraulic head required to induce seepage flow through the PFP, and the investigation of flow and transport dynamics in this specific PFP as opposed to the larger-scale studies previously mentioned where transport was influenced by potentially multiple PFPs (Fuchs et al., 2009; Heeren et al., 2010).

\subsection{Seep flow rate measurements}

A series of artificially-induced seep discharge measurements were made by generating different hydraulic heads in the trench, located approximately $2.0 \mathrm{~m}$ from the seep, and measuring the seepage outflow at the streambank face (Figure 2). Hydraulic heads were induced by pumping water at a constant rate from the Barren Fork Creek into the trench using a gasoline-powered water pump (American Honda, Alpharetta, GA). A preliminary pumping period was included (5-10 $\mathrm{min}$ ) prior to measuring the seepage discharge at each of the cor- 

location of the study site (top), trench system and spatial location of preferential flow pathway (PFP) (bottom right), and pictures of the Barren Fork Creek at high stream stage and the trench injection system with injected $\mathrm{KCl}$ / Rhodamine WT solution (bottom left).
Figure 1. Map showing the plan view and side view of the

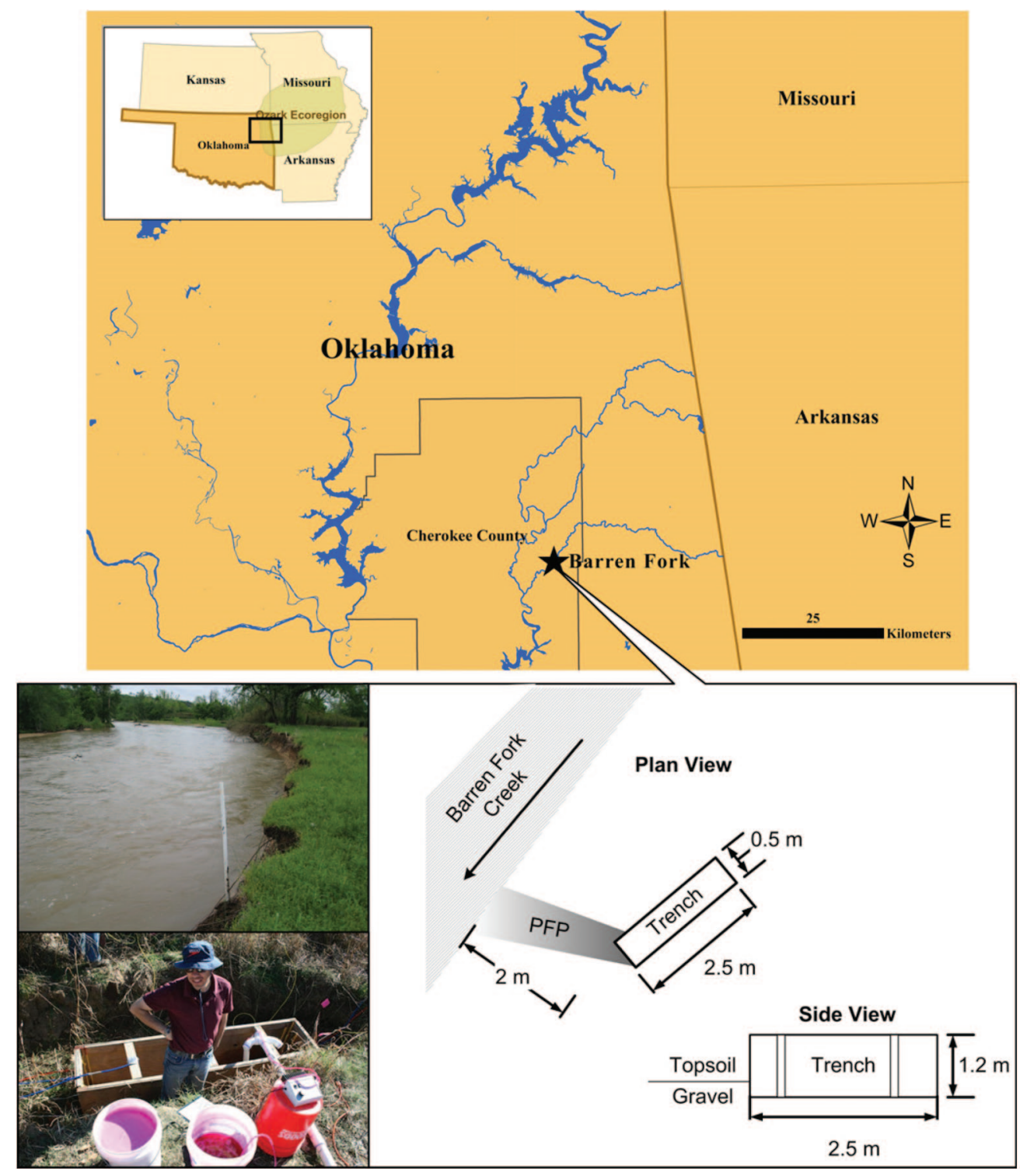

responding hydraulic heads (i.e., approximately 65, 100, 115, and $125 \mathrm{~cm}$ above the seep outflow point). Seep flow was measured using lateral flow collection flumes, as used by Fox et al. (2007) and Wilson et al. (2007), installed just below the seep emergence point. Triplicate measurements of the seep flow were obtained by determining the time required to fill a container of known volume to a specific depth. The average and standard deviations of the seep discharge were calculated and compared relative to the hydraulic head induced in the trench. A sigmoidal function, as used by Fox et al. (2007), was inversely fit to these data to describe the seep discharge versus head relationship.

\subsection{KCl and Rhodamine WT injection tests}

A 125-cm hydraulic head above the seep outflow point was induced by pumping water from the Barren Fork Creek into the trench at approximately $190 \mathrm{~L} / \mathrm{min}$ for roughly $30 \mathrm{~min}$ before injecting $\mathrm{KCl}$ and $\mathrm{RhWT}$. This preliminary pumping period was intended to achieve steady state flow in the PFP prior to injecting the tracers. Samples from the trench (grab sample from the middle of the trench) and steady-state seep flow (grab sample of seep discharge flowing through the lat- eral flow collection flume) were taken prior to the injection to quantify initial conductivity $(185 \mu \mathrm{S} / \mathrm{cm})$ and fluorescence (less than $10 \mu \mathrm{g} / \mathrm{L}$ ) concentrations. Initial concentrations were approximately equivalent between the trench and seep water.

About $50 \mathrm{~L}$ of a $100 \mathrm{mg} / \mathrm{L} \mathrm{KCl}$ (i.e., $50 \mathrm{mg} / \mathrm{L} \mathrm{Cl}^{-}$) and $60 \mathrm{mg} / \mathrm{L}$ RhWT solution were input into the trench from an inflow tank over a 60-min period. The tracer and RhWT solution was dispersed as much as possible using a PVC T-joint. Injection from the inflow tank to the trench was initiated by opening a valve, whose position remained constant throughout the experiment. Therefore, as the head in the inflow tank decreased, the mass flow rate of the $\mathrm{KCl}$ and RhWT solution decreased into the trench, leading to a trench concentration that increased to a peak, declined exponentially, and then decreased sharply after the 60-min injection period. While this injection strategy failed to produce a Dirac or pulse input boundary condition, the actual input boundary condition was numerically modeled with both equilibrium and nonequilibrium conventional convective-dispersion equations (CDEs) using step impulses.

Continuous manual stirring of the trench throughout the $125-\mathrm{cm}$ head occurred during the injection in an attempt to create as uniform a boundary condition as possible. Dur- 
Figure 2. (a) Illustration of the Barren Fork Creek streambank and seep emerging from the streambank. Observation wells shown in the figure were originally installed by Fuchs et al. (2009). (b)

Approximately 50 -cm wide by 10 $\mathrm{cm}$ thick clean, coarse gravel of the seep surrounded by gravel with finer particles. (c) Relationship between the induced hydraulic head and the seep discharge, measured using a lateral flow collection pan. Error bars for each data point represent one standard deviation from the average measured flow rate. Dashed line is a best-fit sigmoidal relationship.

ing and after the injection, samples were obtained from the trench (grab sample from the middle of the trench) and the seep (composite sample from discharge flowing through the lateral collection flume) at equivalent times. Samples were transported back to the laboratory for analysis. Electrical conductivity was measured using an OAKTON pH/CON 510 conductivity meter (OAKTON Instruments, Vernon Hills, IL) with a range of $0-1999 \mu \mathrm{S} / \mathrm{cm}$ and resolution of $1 \mu \mathrm{S} / \mathrm{cm}$ for EC. The RhWT concentrations were measured with a Trilogy laboratory fluorometer (Turner Designs, Inc., Sunnyvale, CA), which had a minimum detection limit of $10 \mu \mathrm{g} / \mathrm{L}$.

\subsection{Transport modeling with CXTFIT}

Flow through the PFP and emerging as a seep at the streambank was idealized as one-dimensional flow through saturated porous media. One research question was whether a one-dimensional solution could represent the observed concentration breakthrough curves. One-dimensional solutions to the CDE may not be valid and fit the breakthrough data if the vertical thickness or width of the PFP changes along the $2 \mathrm{~m}$ flow path. The EC and RhWT concentration breakthrough curves were modeled using CXTFIT (version 2.1) (Toride et al., 1999), a model used extensively for simulating solute transport through soils (e.g., [Beven et al., 1993; Gwo et al., 1995; Baumann et al., 2002; Lee et al., 2002). CXTFIT solves various boundary value, initial value, and production value problems (Toride et al., 1999). The program uses a nonlinear least-squares parameter optimization method to derive solute transport parameters for various model formulations. The equilibrium CDE with the assumptions of steady-state flow, no degradation of the solute in the liquid or adsorbed phases, and no production of the solute within the simulation domain is given by the following equation:

$$
R \frac{\partial c}{\partial t}=D^{(h)} \frac{\partial^{2} c}{\partial x^{2}}-v \frac{\partial c}{\partial x}
$$

where $c$ is the concentration of the solute in the liquid phase, $D^{(h)}$ is the dispersion coefficient, $v$ is the average pore-water velocity, $t$ is time, $x$ is the spatial distance, and $R$ is the retarda- (a)

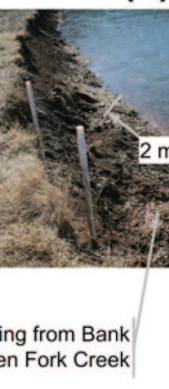

(b)

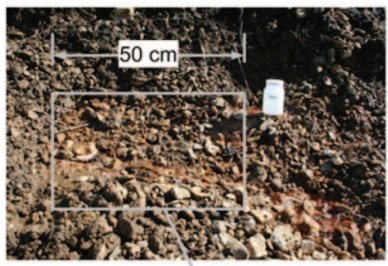

Clean, Coarse Gravel of Seep Surrounded by Gravel with Finer Particles
Observation Wells Approximately $2.0 \mathrm{~m}$ from the Trench

(c)

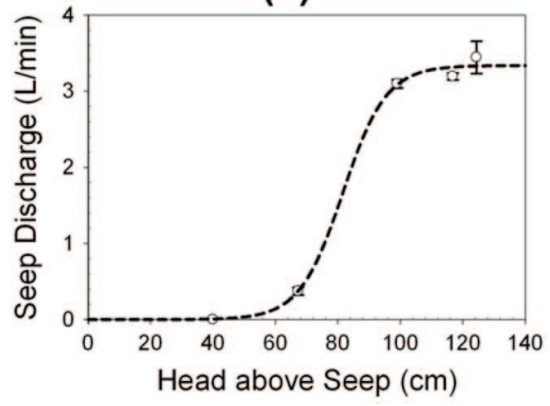

tion coefficient given by the following equation:

$$
R=1+\frac{K_{d} \rho_{b}}{\theta}
$$

where $\rho_{b}$ is bulk density, $\theta$ is the volumetric water content, and $K_{d}$ is the distribution coefficient for sorption (Toride et al., 1999).

The model also solves a two-site (TS) chemical nonequilibrium model and a two-region (TR) physical nonequilibrium model (Brusseau et al., 1991; Brusseau, 1998; Wilson et al., 1998). These two models can be expressed by the same dimensionless equations for linear sorption and steady-state water flow (where degradation and solute production has been appropriately neglected for this research):

$$
\begin{aligned}
& \beta R \frac{\partial C_{1}}{\partial T}=\frac{1}{P} \frac{\partial^{2} C_{1}}{\partial Z^{2}}-\frac{\partial C_{1}}{\partial Z}-\omega\left(C_{1}-C_{2}\right) \\
& (1-\beta) R \frac{\partial C_{2}}{\partial T}=\omega\left(C_{1}-C_{2}\right)
\end{aligned}
$$

where the subscripts 1 and 2 refer to equilibrium and nonequilibrium sites, respectively, $C$ is the dimensionless concentration $\left(c / c_{o}\right.$, where $c_{o}$ is the input concentration), $T$ is dimensionless time, $Z$ is dimensionless distance, $P$ is the Peclet number (Equation (5)), $\beta$ is a dimensionless partitioning coefficient (Equation (6)), and $\omega$ is a dimensionless mass transfer coefficient (Equation (7)):

$$
\begin{aligned}
& P=\frac{v L}{D^{(h)}} \\
& \text { TS: } \quad \beta=\frac{\theta+f \rho_{b} K_{d}}{\theta+\rho_{b} K} \\
& \text { TR: } \quad \beta=\frac{\theta_{m}+f \rho_{b} K_{d}}{\theta+\rho_{b} K_{d}} \\
& \text { TS: } \omega=\frac{\alpha(1-\beta) R L}{v} \\
& \text { TR: } \omega=\frac{\alpha L}{\theta v}
\end{aligned}
$$


where $f$ is the fraction of equilibrium exchange sites, $\theta_{m}$ is the volumetric water content of the mobile fluid region, $L$ is a characteristic length scale, and $\alpha$ is a first-order mass transfer coefficient (Toride et al., 1999).

The EC and RhWT input boundaries at the trench were input as a series of step impulses into CXTFIT because of the inflow strategy. Following the procedure by Pang and Close (1999), equilibrium and TR models in CXTFIT were first applied to the seep EC data with $R=1$. The equilibrium model was used to inversely estimate $v$ and $D^{(h)}$. The TR model examined the presence of physical nonequilibrium of the conservative solute and inversely estimated $v, D^{(h)}$, the fraction of immobile water (i.e., $\beta=\theta_{m} / \theta$ ), and $\omega$. The $\beta$ value was used to assess the importance of physical nonequilibrium: $\beta<1$ suggested some fraction of immobile region water (Pang and Close, 1999).

Equilibrium and nonequilibrium models were fit to the RhWT data, assuming that $v$ and $D^{(h)}$ derived from the EC modeling were solute independent. Sorption was included $(R>1)$ for RhWT since RhWT is known to slightly sorb in some subsoils (Sabatini, 1999; Sutton et al., 2000; Flury and Wai, 2003). Note that chemical nonequilibrium has been reported to occur for fluorescent dyes, increasing the spreading of dye breakthrough curves (Sabatini, 1999).

\section{Results and discussion}

The seep emerged at the streambank in a coarse gravel layer approximately $50 \mathrm{~cm}$ wide and $10 \mathrm{~cm}$ thick (see Supplemental video, Streambank Seep). It was approximately $1.9 \mathrm{~m}$ below the ground surface, which was consistent with previous characterization of the PFP using electrical resistivity (Heeren et al., 2010). The PFP from which the seep originated was clean gravel surrounded by gravel with finer particles (Figure 2). The percent of material finer than $2.0 \mathrm{~mm}$ confirmed this observation. Furthermore, disturbed samples and electrical resistivity measurements from the PFP closely mimicked samples from a recent gravel bar deposit just upstream of the seep (Heeren et al., 2010; Miller et al., 2010). These results supported the hypothesis that the PFP was a buried gravel bar.

The PFP required approximately $40 \mathrm{~cm}$ of hydraulic head for flow to emerge at the streambank (Figure 2). The reason for this minimum head requirement was that the gravel and finer material surrounding the PFP possessed a relatively large hydraulic conductivity and therefore promoted significant mass transfer into the soil in the up-gradient section of the PFP. Heeren et al. (2010) suggested a similar phenomenon when observing results from a floodplain-scale RhWT injection study. Their study demonstrated that the transport of RhWT was affected by the PFP but also mimicked the general ground water flow direction as water containing the tracer recharged the ground water system. Therefore, at smaller hydraulic heads, the PFP may impact the distribution of water and solutes in the floodplain without surfacing at the streambank.

As the head above the seep increased, discharge from the seep reached a maximum of approximately $3.5 \mathrm{~L} / \mathrm{min}$ (Figure 2). In order to generate a hydraulic head of $125 \mathrm{~cm}$ above the seep, the required pumping rate into the trench was approximately $190 \mathrm{~L} / \mathrm{min}$. Therefore, flows emerging at the streambank through this particular PFP represented approximately $2 \%$ of the total flow injected into the trench. The hydraulic heads induced on the seep were reasonable compared to flow rates reported by other studies when measuring natural streambank seeps. Fox et al. (2007) and Wilson et al. (2007) reported seep flow rates on the order of $1.0 \mathrm{~L} / \mathrm{min}$. A one-dimensional conceptualization of the PFP flow was more reasonable at higher heads when exfiltration into non-PFP subsoil was hypothesized to be small compared to discharge through the PFP.
Background EC levels were approximately $185 \mu \mathrm{S} / \mathrm{cm}$; no detectable (i.e., less than $10 \mu \mathrm{g} / \mathrm{L}$ ) RhWT was measured in background samples. The injected $\mathrm{KCl}$ solution increased the trench EC to a $500 \mu \mathrm{S} / \mathrm{cm}$ peak concentration, and the RhWT injection resulted in peak RhWT concentrations slightly less than $400 \mu \mathrm{g} / \mathrm{L}$. The RhWT was visually observed in the seep less than two to three minutes after injection into the trench was initiated (see Supplemental video, Streambank Seep). Also, as observed by Fuchs et al. (2009) and Heeren et al. (2010), RhWT was detected in the two observation wells that surrounded the seep during injection, but not in other adjacent observation wells located equivalent distances from the trench.

The shape of the step impulses input into CXTFIT for the trench mimicked the measured trench EC and RhWT concentrations (Figure 3). Nine step impulses were used for the EC boundary condition (Figure 3a), and twelve step impulses were used for the RhWT boundary condition (Figure 3b). The number and duration of step inputs for EC and RhWT were fit by trial and error to obtain the best match to the input boundary condition. The equilibrium CDE with no retardation was able to match the observed EC breakthrough curve with a coefficient of determination, $R^{2}$, of 0.94 (Figure 4a). The inversely estimated ground water flow velocity, $u$, and dispersion coefficient, $D^{(h)}$, suggested rapid movement of the $\mathrm{KCl}$ tracer from the trench to the seep. In fact, estimated $u$ from CXTFIT was $26.2 \mathrm{~m} / \mathrm{h}$ or $630 \mathrm{~m} / \mathrm{d}$. Using an estimated induced hydraulic gradient $(0.625 \mathrm{~m} / \mathrm{m})$ and porosity $(0.4)$, the estimated hydraulic conductivity of the PFP was approximately $400 \mathrm{~m} / \mathrm{d}$. Fuchs et al. (2009) measured hydraulic conductivities of the gravel subsoil on the order of $140-230 \mathrm{~m} / \mathrm{d}$ using falling-head tests in
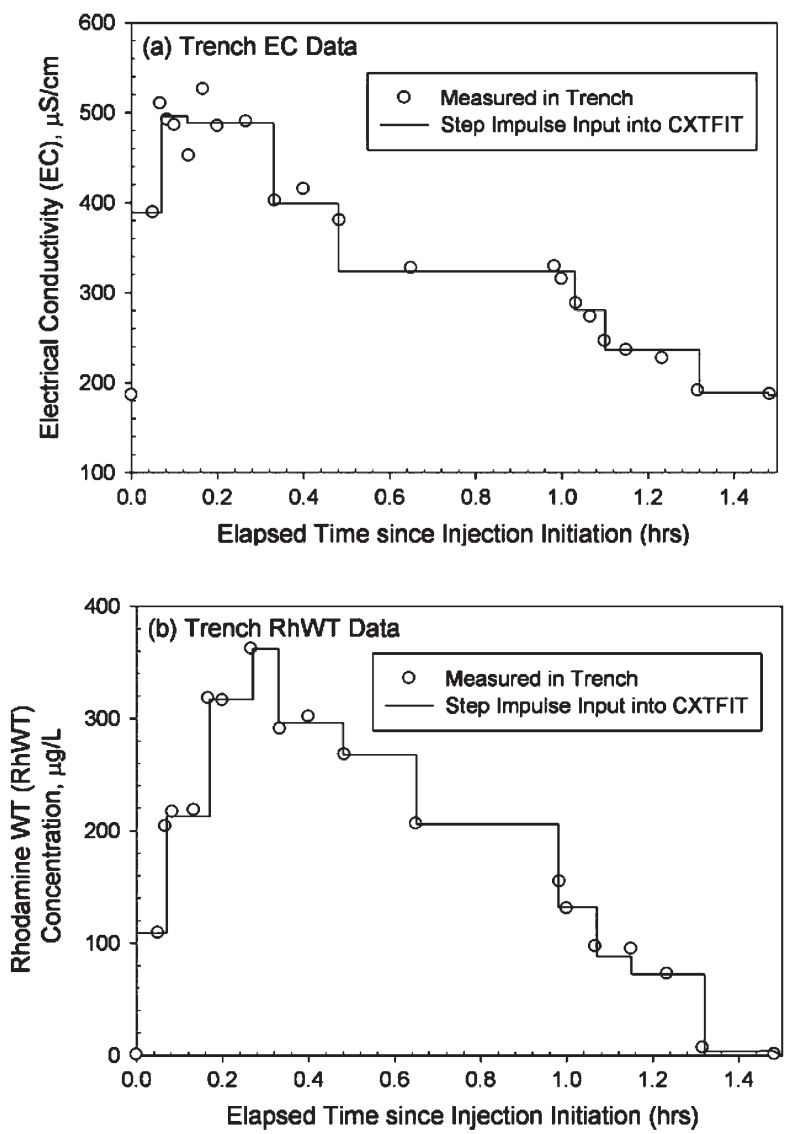

Figure 3. (a) Electrical conductivity (EC) and (b) Rhodamine WT (RhWT) concentrations measured in the trench during the transport experiments and the step impulse input boundary conditions for CXTFIT (version 2.1). 
the trench, so values derived in this research were deemed reasonable based on the fact that the previous estimate was an integrated measurement over PFP and non-PFP flow domains.

The large $D^{(h)}$ and therefore small Peclet number suggested that the 2-m long PFP behaved more like a completely mixed system (dispersion dominated) as opposed to a plug flow system. Dispersion is the only cause of spreading of the breakthrough curve for EC in an equilibrium model; previous researchers have suggested that high values of $D^{(h)}$ may be unrealistic if physical nonequilibrium is present (Pang and Close, 1999). The TR model predicted an EC breakthrough curve equivalent to the equilibrium model results with an equivalent $R^{2}$ (Figure 4a). However, depending upon the initial parameter values specified in the inverse routine, non-unique solutions were obtained for the parameter estimates and the standard errors of the inversely estimated parameters were large; therefore, physical equilibrium was assumed to be an adequate representation of the transport process.

Application of the equilibrium and nonequilibrium models to the RhWT breakthrough curves resulted in similar conclusions. The equilibrium model predicted the observed breakthrough with an equivalent $R^{2}=0.91$ when using appropriate parameters from the EC data (Figure $4 \mathrm{~b}$ ). The equilibrium model predicted a retardation coefficient, $R$, of 1.30 , which resulted in a $K_{d}$ of $0.1 \mathrm{~cm}^{3} / \mathrm{g}$ (i.e., a highly mobile solute) when using typical values of the bulk density and porosity from Fuchs et al. (2009). Some of the discrepancy between model predictions and observed RhWT seep concentrations was due to the limitations associated with using assumed step impulses for the RhWT input boundary condition in the trench as opposed to having real-time data for the boundary concentration
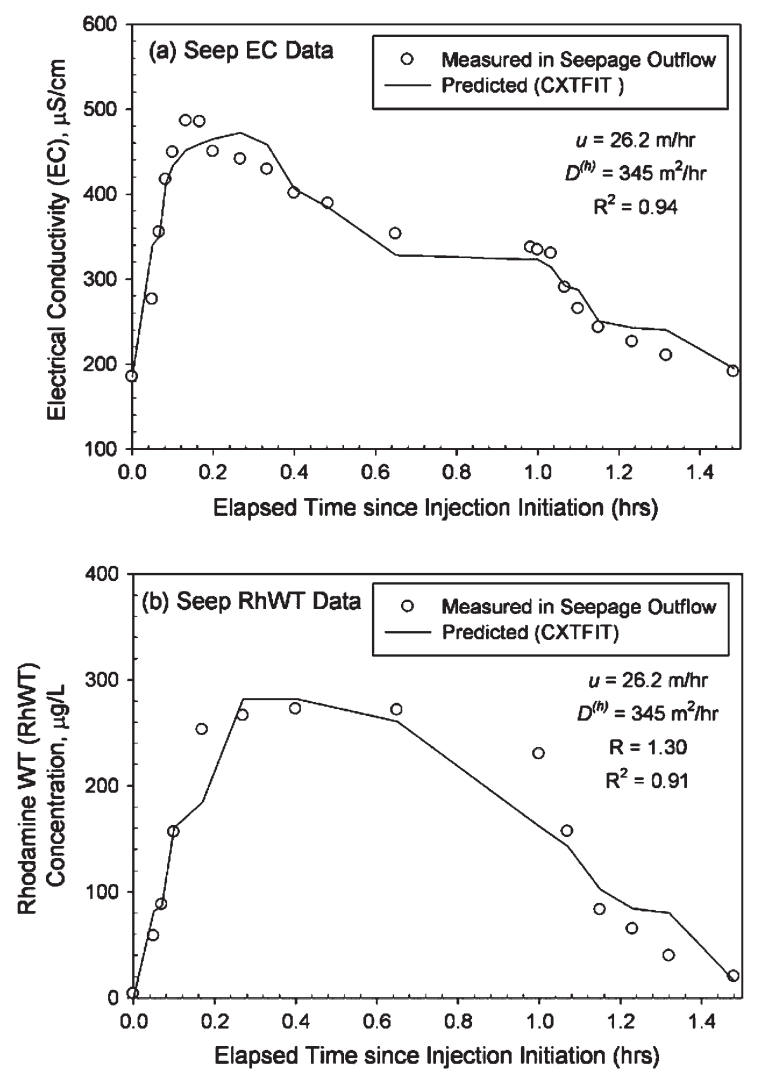

Figure 4. (a) Electrical conductivity (EC) and (b) Rhodamine WT (RhWT) concentrations measured in the seep outflow during the transport experiments and the predicted solute concentration using equilibrium models in CXTFIT (version 2.1). Nonequilibrium model predictions were equivalent for both EC and RhWT.
(Figure 3). The nonequilibrium model for RhWT exhibited the same properties as the nonequilibrium model for EC: (1) it did not improve the fit between measured and observed RhWT seep breakthrough in terms of the $R^{2}$; (2) non-unique parameter sets were obtained depending on the initial parameter estimates; and (3) the standard errors of the inversely estimated parameters were large. Similar to the EC, equilibrium was assumed to be an adequate representation of the transport process.

The previous CXTFIT simulations provided guidance regarding reactive solute transport of phosphorus, a primary water quality constituent of concern in this watershed. Fuchs et al. (2009) reported a phosphorus $K_{d}$ of $4.5 \mathrm{~L} / \mathrm{kg}$ for fine material (i.e., less than $2.0 \mathrm{~mm}$ ) in the gravel substrate at the Barren Fork Creek site. Using the $6 \%$ estimate for fine material content and typical values of the bulk density and porosity, the $R$ for phosphorus transport in the PFP would range from 2.0 to 2.4 , only slightly greater than the $R$ for RhWT. Therefore, phosphorus reaching the PFP from infiltration would be rapidly transmitted in the PFP.

Of course, phosphorus in these floodplain systems may be more associated with colloid-sized soil particles, which could still be subject to piping through the PFP (Schelde et al., 2006; Fuchs et al., 2009; Heeren, 2011), rather than being dissolved, and therefore the calculated $K_{d}$ may be conceptually inappropriate. Future work is needed to investigate this question. An additional question yet to be answered is the leaching potential for phosphorus in these cherty soils. The potential for phosphorus leaching is commonly estimated based on point-measurements of soil test phosphorus (STP) or measurements of the sorption capability of disturbed soil samples representing the soil matrix. However, macropores and gravel outcrops, which have been frequently observed in these riparian floodplains, may have a significant impact on water movement to the PFPs, and current research is underway to quantify leaching potential.

\section{Summary and conclusions}

Limited data have been reported on the flow and transport dynamics of preferential flow pathways. Unique to this research was the quantification of hydraulic parameters for the preferential flow pathway (i.e., hydraulic conductivity on the order of $400 \mathrm{~m} / \mathrm{d}$ and flow velocity greater than $26 \mathrm{~m} / \mathrm{h}$ with a hydraulic gradient of approximately $0.63 \mathrm{~m} / \mathrm{m}$ ), the determination of the hydraulic head required to induce seepage (i.e., $40 \mathrm{~cm}$ approximately $2 \mathrm{~m}$ from the streambank seep), and an investigation of flow and transport dynamics in this specific pathway (i.e., conceptualization of a one-dimensional flow path) as opposed to previously-reported larger-scale studies at the site.

The pathway from which the seep originated was a localized zone of relatively clean gravel (6\% fines by mass) surrounded by gravel with finer particles ( $20 \%$ fines by mass). For this riparian floodplain, water flowing through the preferential flow pathway moved into the gravel material in the up-gradient reaches of the PFP and in soils surrounding the pathway. Therefore, the pathway required high heads to exfiltrate the bank as a ground water seep. It may also play an influential role as a free-drainage system for the riparian area that could limit saturation-excess Hortonian overland flow to the stream. The pathway will likely be active during high stream stage periods and redistribute water and solutes across a larger area of the floodplain by bank storage of stream water.

The breakthrough curves of electrical conductivity and Rhodamine WT highlighted the almost immediate appearance of the solutes at the streambank face after injection into the trench approximately $2 \mathrm{~m}$ away. One-dimensional convective-dispersion models were able to match the electrical conductivity and Rhodamine WT breakthrough curves at a high hydraulic head 
when exfiltration into non-PFP subsoil was hypothesized to be small compared to discharge through the seep. The electrical conductivity breakthrough curve suggested physical equilibrium within the system, although transient storage of flow and solutes is expected on the boundary of the preferential flow pathway. The inversely estimated transport parameters for the preferential flow pathway, when combined with previous estimates of phosphorus retardation in these gravel soils, suggested that phosphorus reaching the pathway from infiltration would be rapidly transmitted to the stream.

Acknowledgments - This material is based upon work supported by the Oklahoma Conservation Commission with a US Environmental Protection Agency Region VI 319 grant. The authors acknowledge Dan Butler of the Oklahoma Conservation Commission for providing access to the riparian floodplain property. The authors also acknowledge Glenn V. Wilson, USDA-ARS, Oxford, MS; Amanda K. Fox, Stillwater, OK, and Alan E. Fryar, University of Kentucky, Lexington, KY for reviewing an earlier version of this manuscript; and Norman E. Fox, Godley, TX, for assisting with construction of the trench.

\section{Supplementary material}

A 1-minute supplementary video of the experiment is attached at the URL cover page for this article, at

http://digitalcommons.unl.edu/biosysengfacpub/224

\section{References}

Amoros, C., Bornette, G., 2002. Connectivity and biocomplexity in waterbodies of riverine floodplains. Freshwater Biol. 47, 761-776.

Andrews, W.J., Becker, M.F., Smith, S.J., Tortorelli, R.L., 2009. Summary of Surface-Water Quality Data from the Illinois River Basin in Northeast Oklahoma, 1970-2007. Scientific Investigations Report 2009-5182. US Geological Survey, Reston, VA.

Baumann, T., Muller, S., Niessner, R., 2002. Migration of dissolved heavy metal compounds and PCP in the presence of colloids through a heterogeneous calcareous gravel and a homogeneous quartz sand-pilot scale experiments. Water Res. 36 (5), 1213-1223.

Beven, K.J., Henderson, D.E., Reeves, A.D., 1993. Dispersion parameters for undisturbed partially saturated soil. J. Hydrol. 143 (1-2), 19-43.

Brusseau, M.L., 1998. Multiprocess nonequilibrium and nonideal transport of solutes in porous media. In: Selim, H.M., Ma, L. (Eds.), Physical Nonequilibrium in Soils: Modeling and Application. Chelsea, MI, Ann Arbor Press.

Brusseau, M.L., Larsen, T., Christensen, T.H., 1991. Rate-limited sorption and nonequilibrium transport of organic chemicals in low organic carbon aquifer materials. Water Resour. Res. 27, 1137-1145.

Chu-Agor, M.L., Fox, G.A., Cancienne, R., Wilson, G.V., 2008. Seepage caused tension failures and erosion undercutting of hillslopes. J. Hydrol. 359 (3-4), 247-259.

Chu-Agor, M.L., Fox, G.A., Wilson, G.V., 2009. Empirical sediment transport function predicting seepage erosion undercutting for cohesive bank failure prediction. J. Hydrol. 377 (1-2), 155-164.

Duval, T.P., Hill, A.R., 2006. Influence of stream bank seepage during low-flow conditions on riparian zone hydrology. Water Resour. Res. 42 (10), W10425.

Duval, T.P., Hill, A.R., 2007. Influence of base flow stream bank seepage on riparian zone nitrogen biogeochemistry. Biogeochemistry 85 (2), 185-199.

Flury, M., Wai, N.N., 2003. Dyes as tracers for vadose zone hydrology. Rev. Geophys. 41, 1002. doi:10.1029/2001RG000109.

Fox, G.A., Wilson, G.V., 2010. The role of subsurface flow in hillslope and streambank erosion: a review. Soil Sci. Am. J. 74 (3), 711-733.

Fox, G.A., Wilson, G.V., Simon, A., Langendoen, E., Akay, O., Fuchs, J.W., 2007. Measuring streambank erosion due to ground water seepage: correlation to bank pore water pressure, precipitation, and stream stage. Earth Surf. Proc. Land 32 (10), 1558-1573.

Fuchs, J.W., Fox, G.A., Storm, D.E., Penn, C., Brown, G.O., 2009. Subsurface transport of phosphorus in riparian floodplains: influence of preferential flow paths. J. Environ. Qual. 38 (2), 473-484.

Gwo, J.P., Jardine, P.M., Wilson, G.V., Yeh, G.T., 1995. A multiplepore-region concept to modeling mass transfer in subsurface media. J. Hydrol. 164 (1-4), 217-237.
Heeren, D.M., Miller, R.B., Fox, G.A., Storm, D.E., Halihan, T., Penn, C.J., 2010. Preferential flow effects on subsurface contaminant transport in alluvial floodplains. T. ASABE 53 (1), 127-136.

Heeren, D.M., Fox, G.A., Miller, R.B., Storm, D.E., Fox, A.K., Penn C.J., Halihan, T., Mittelstet, A.R., in press. Stage-dependent transient storage of phosphorus in alluvial floodplains. Hydrol. Process, doi:10.1002/hyp.8054.

LaSage, D.M., Sexton, J.L., Mukherjee, A., Fryar, A.E., Greb, S.F., 2008. Groundwater discharge along a channelized coastal plain stream. J. Hydrol. 360 (1-4), 252-264.

Lee, J., Horton, R., Jaynes, D.B., 2002. The feasibility of shallow time domain reflectometry probes to describe solute transport through undisturbed soil cores. Soil Sci. Soc. Am. J. 66, 53-57.

Lindow, N., Fox, G.A., Evans, R.O., 2009. Seepage erosion in fluviomarine stream bank material. Earth Surf. Proc. Land 34 (12), 1693-1701.

Miller, R.B., Heeren, D.M., Fox, G.A., Halihan, T., Storm, D.E., Mittelstet, A.R., 2010. Use of multi-electrode resistivity profiling to estimate saturated- and vadosezone hydraulic properties of preferential flow paths in alluvial floodplains in the Ozark region of eastern Oklahoma. In: Proceedings of the ASCE EWRI World Environmental and Water Resources Congress. Reston, VA, ASCE.

Modica, E., Burton, H.T., Plummer, L.N., 1998. Evaluating the source and residence times of groundwater seepage to streams, New Jersey Coastal Plain. Water Resour. Res. 24 (11), 2797-2810.

Naiman, R.J., Decamps, H., McClain, M.E., 2005. Catchments and the physical template. In: Naiman, R.J. (Ed.), Riparia: Ecology, Conservation, and Management of Streamside Communities. Elsevier Academic Press, Boston, MA.

National Research Council (NRC), Committee on Hydrologic Science (COHS), 2004. Groundwater Fluxes across Interfaces. The National Academies Press, Washington, DC.

O'Driscoll, M.A., DeWalle, D.R., 2010. Seeps regulate stream nitrate concentrations in a forested Appalachian catchment. J. Environ. Qual. 39 (1), 420-431.

Pang, L., Close, M.E., 1999. Non-equilibrium transport of Cd in alluvial gravels. J. Contam. Hydrol. 36, 185-206.

Poole, G.C., Naiman, R.J., Pastor, J., Stanford, J.A., 1997. Uses and limitations of ground penetrating RADAR in two riparian systems. In: Gibert, J., Mathieu, J., Fournier, F. (Eds.), Groundwater/Surface Water Ecotones: Biological and Hydrological Interactions and Management Options. Cambridge University Press, Cambridge.

Sabatini, D.A., 1999. Sorption and intraparticle diffusion of fluorescent dyes with consolidated aquifer media. Ground Water 38 (5), 651-656.

Schelde, K., de Jonge, L.W., Kjaergaard, C., Laegdsmand, M., Rubaek, G.H., 2006. Effects of manure application and plowing on transport of colloids and phosphorus to tile drains. Vadose Zone J. 5 (1), 445-458.

Stanford, J.A., Ward, J.V., 1992. Management of aquatic resources in large catchments: Recognizing interaction between ecosystem connectivity and environmental disturbance. In: Naiman, R.J. (Ed.), Watershed Management. New York, Springer-Verlag.

Sutton, D.J., Kabala, Z.J., Vasudevan, D., 2000. Rhodamine WT as a reactive tracer: Laboratory studies and field consequences. In: Dassargues, A. (Ed.), Tracers and Modelling in Hydrogeology. IAHS Publication No. 262. IAHS Press, Oxfordshire, UK.

Toride, N., Leij, F.J., van Genuchten, M.Th., 1999. The CXTFIT Code for Estimating Transport Parameters from Laboratory or Field Tracer Experiments, Version 2.1. Research Report No. 137. Riverside, CA, US Salinity Laboratory, Agricultural Research Service, Department of Agriculture, United States.

Wagenet, R.J., Chen, W., 1998. Coupling sorption rate heterogeneity and physical nonequilibrium in soils. In: Selim, H.M., Ma, L. (Eds.), Physical Nonequilibrium in Soils: Modeling and Application. Ann Arbor Press, Chelsea, MI.

Wilson, G.V., Gwo, J.P., Jardine, P.M., Luxmoore, R.J., 1998. Hydraulic and physical nonequilibrium effects on multiregion flow. In: Selim, H.M., Ma, L. (Eds.), Physical Nonequilibrium in Soils: Modeling and Application. Ann Arbor Press, Chelsea, MI.

Wilson, G.V., Periketi, R., Fox, G.A., Dabney, S., Shields, F.D., Cullum, R.F., 2007. Soil properties controlling seepage erosion contributions to streambank failure. Earth Surf Proc. Land 32 (3), 447-459. 